\title{
Prioritizing and Analyzing Key Factors of Succeeding Knowledge-Based Organizations Using Analytical Hierarchy Process (AHP)
}

\author{
Somayeh Hosseinzadeh ${ }^{1}$, Toraj Mojibi ${ }^{2 *}$, Seyyed Mehdi Alvani ${ }^{3}$, Javad Rezaeian ${ }^{4}$ \\ ${ }^{1}$ Department of Management, Islamic Azad University, Firoozkooh Branch, Iran \\ ${ }^{2}$ Department of Management, Islamic Azad University, Firoozkooh Branch, Iran \\ ${ }^{3}$ Department of Management, Islamic Azad University, Qazvin and Firoozkooh Branch, Iran \\ ${ }^{4}$ Department of Industrial Engineering, Science and Technology University of Mazandaran, Babol, Iran
}

\section{Keywords:}

behavioral criteria, cultural criteria,

knowledge-based

organization,

structural criteria

\section{Received}

10 August 2019

Received in revised form

03 November 2019

Accepted

27 November 2019

Correspondence:

toragmogibi@yahoo.com

\begin{abstract}
In this knowledge era, educational institutes and researchers are considered fundamental developing bases for societies, and thus identifying and prioritizing key factors of succeeding knowledge-based organizations is an undeniable requirement. Therefore, the present study identifies and prioritizes key factors of succeeding knowledge-based organizations and defines their importance level. The data were collected through research-made questionnaire. The content validity and reliability of the questionnaire were reported. By distributing questionnaires among experts, and adding or removing some regulations, eighteen factors were ultimately categorized into three groups. The results obtained from analytical hierarchy process (AHP) revealed that the significant key factors of succeeding knowledge-based organization are cultural, structural, and behavioral criteria, respectively. These results help managers in developing knowledgebased organization.
\end{abstract}




\section{Introduction}

Knowledge management outstandingly focuses on the knowledge-based activities and helps create, capture, transform, and use the knowledge (Cavaleri, 2004). In every organization, many resources play key roles. Knowledge is one such resource, which is increasingly being regarded by some organizations as an important asset in creating the company' s competitive advantage (Chang, Hung, Yen, \& Tseng, 2009). The knowledge management contributes to organizational development in the sense that the employees of each of the organization's departments know how to use knowledge in their work processes (de Barros Jerônimo et al., 2018).

In the present knowledge era, educational organizations and researchers are considered developing bases in societies and knowledge management has gained a high importance. Currently, economic, environmental, and humanity resources are not efficient individually for development. Knowledge is viewed as a major resource and agent of development. The application ability of knowledge and potentials like intelligence and new solution creating for meeting human needs has a superior position in global system and knowledge creating has become a major factor in world development and improvement. Competitive advantage of organizations and societies is "knowledge" and country winning against each other depends on knowledge power (Alvani, 2008). Tocan (2012) believes that power and wealth is achieved by imperceptible mental resource, which is knowledge asset. Therefore, embedding the resource into societies contributes with an exclusive and deep process and change in social elements. Few organizations and institutions are interested in knowledge-based concept and move towards to this asset in these circumstances. This attitude needs modern managerial methods, techniques, technology and strategies. In other words, these changes make a new kind of management - knowledge-based management and a new kind of organization - knowledge-based organization.

\section{Research Theoretical Structures}

Key elements in succeeding knowledge-based organization are different in the viewpoint of theorists. Many studies implicate that there is no single theory about this subject. Given succeeding knowledge management, some theories focus on structural and technological factors, some of them consider human and cultural factors, and others take their combination into account as the critical function. Martina et al (2012) describe knowledge-based organization as an organization with a knowledge-based approach. In this approach, organization is considered an instrument for developing, integrating, securing, sharing and applying knowledge. According to their views, it is possible to take into account following characteristics for knowledge-based organization: developing, integrating, sharing and applying knowledge, efficient, creative, flexible and active, customer based, using IT- with an open and steady organizational culture - implementing knowledge processes, discovering knowledge resources, intelligent, risk management, implementing project management, emphasis on training and learning of organization, encouraging knowledge personnel, process based, supporting teamwork, and participating in managing.

Organizations should consider that modeling knowledge-based organization concept results from different components including: learning organization, invention, mental assets and human sources, knowledge-based systems, information management, communication and information technologies, leading and organizational structure, organizational strategies and goals and other things. These components are presumed as substantial elements in determining existence philosophy of these organizations. Few organizations understand the real meaning of being knowledge-based and how to make a knowledge-based organization due to lack of an exclusive 
model for determining knowledge-based organizations (Zack, 2003). In order to establish a knowledge-based organization, all key factors of its successfulness should be considered. Transforming to a knowledge-based organization calls for different organizational factors such as organizational structure, culture and behavior. They have special features and should involve necessary integrity and contribution as elaborated below.

\section{Organizational Structure}

Knowledge-based structures require creativity, introduction, capability and synchronization. For attaining such an environment, a structure allowing modern knowledge building, information free stream, exploiting and influencing new ideas should be adopted and support features like autonomy, excessive professionalism, independency, freedom and high organizational mobility. Three important components of structure include centralization, formalization and complexity. The centralization emphasizes the rights of decision making and evaluating activities in a specific part of organization. The formalization means how organization applies the regulations and rules. The purpose of complexity is the amounts of tasks or subsystems existed in the organization and has specific roles (Liao, Chang, \& Wu, 2010).

Creating knowledge requires flexibility and less emphasis on task regulations. When serious formal regulations are dominant in an organization, developing modern ideas is limited. Complexity in decision making rights restricts providing creative solutions, but power distribution in organization leads to autonomy, experience and freedom of expression (Graham \& Pizzo, 1996). A non-centralized organizational structure provides an environment in which employees voluntarily participate in creating and facilitating knowledge (Starbuck, 1992). Examining required properties for organizations about knowledge and its management implicates that formal criteria and its extreme elements are not sufficient for this responsiveness condition, and have to take deeper structural factors into accounts (Monavvarian, Kheir Andish, \& Asgari, 2013) that are described below:

\section{Eliminating of Boundary}

Knowledge-based organizations need being free from separating restrictive boundaries and need a common mental framework in order to develop organizational identity and reliability-based relations through it. This saving organizational knowledge may spread over physical boundary restrictions. It makes organization employees to access information without any prohibitions from formal controls and authorities. Informal relations play an important role in eliminating these boundaries (Zahedi \& Kheir Andish, 2008).

\section{Fluidity}

Effective knowledge management requires fluid stream of knowledge not its accumulation. Organizational structure should facilitate knowledge fluidity and allows knowledge deep influence on the performance. Informal relations promote proper local and abroad networks for establishing knowledge stream (Monavvarian et al., 2013).

\section{Using Teams and Awarding Them}

Teams are becoming a major component. This is because of excessive dependence of duties, shifting in organizing methods, more smoothing of organizations and technology changes. One of the most important duties in successful knowledge management is the organizing multi-task teams 
for obtaining knowledge and providing it in the easiest possible way (Goh, 2002). However, group designing in evaluating systems of performance and compensation may induce individuals to help each other for improving performance level and supporting people and sharing knowledge among group members (Miller \& Droge, 1986).

\section{Flexibility}

In order to produce knowledge-based structure effectively, it has to be flexible not definite, which allows to reorganize knowledge timely and properly and gather individuals and units for meeting organizational requirements. Therefore, they cannot be inflexible frameworks, but they are dynamic phenomena, which make different processes and reappear. This commitment is provided through informal relations (Wang \& Ahmed, 2003).

\section{Information Technology}

According to theorizers, information technology is one of the most important key factors in succeeding knowledge-based organization. Using information technology may reduce sequential levels and accelerate doing tasks. Wang and Ahmed (2003) believes that these technologies make enriched knowledge-based organization and are considered the most efficient instrument for collecting, saving, transferring and outspreading knowledge.

\section{Organizational Culture}

Organizational culture is an organizational feature that is likely to affect the success of any knowledge management approach, which has an important effect on the technology implementation, comprehensive management, and etc. (Stock, McFadden, \& Gowen, 2007). However, each organization has its own unique culture that over time reflects the organization identity on both visible and invisible dimensions (Ajmal \& Petri, 2010). Knowledge is possibly contributed to organization efficiently, if it is supported by organizational culture. Knowledge culture advocates knowledge processes and employees regarding knowledge sharing as a normal activity in their daily business. Some components are required in order to develop knowledge-based organization under the light of cultural criteria, which are described as follows:

\section{Trust}

Trust has a strong impact on creating knowledge because of providing various ideas and thought, maintaining and keeping tacit knowledge due to friendly and satisfying atmosphere, knowledge sharing, and people's confidence to each other and knowledge application (Cazier, Shao, \& Louis, 2007). Hsu, Ju, Yen, and Chang (2007) argued that the biggest challenge in nurturing an individual's knowledge sharing behavior in virtual communities is the willingness to share knowledge with others. They concluded that self-efficacy and trust play important roles in guiding individuals' behavior. Based on Social Capital Theory, knowledge sharing between social groups can be promoted if they share common values thus facilitating them to create mutual trust (Liu, 2011).

\section{Participation}

The contribution of knowledge by individuals happens when they believe that participation increases their professional reputation, shares their expertise, and becomes part of the network structure (Wasko \& Faraj, 2005). Monavvarian et al. (2013) believe that participation is necessary for overcoming negative behavior and principles resulting from separating and professionalism and 
supporting contribution and development, maintenance, transmission and sharing and applying knowledge and conflict solutions.

\section{Knowledge Fostering Leading}

Organizational activities should be integrated with knowledge discovering and exploiting in a knowledge-based organization. Also, these organizations should be flexible against changes. To provide this environment, supporting flexibility, knowledge discovery, and enjoyment is possible with knowledge-based leading (Hassani, 2014).

\section{Islamic and Religious Values}

Iranian society as a society depending on Islamic values has to consider these values in bureaucracy policies and this is reflected in the context of general policies of the bureaucracy system. According to the sixteenth paragraph of general policies of bureaucracy system, it is emphasized to make the bureaucracy based on knowledge using knowledge managing principles and integrating information depending on Islamic values (Alvani, 2014).

\section{Meritocracy}

According to meritocracy, individuals evolve their ingenuities by educational system and their mass endeavors, and finally, apart from sexuality, social class, race or wealth, charging a job properly depends on eligibility. Meritocracy means using the best people in the most appropriate position in the organization (Nasr Esfahani \& Nasr Esfahani, 2009). Establishing meritocracy system and using people depending on their ability and qualification results in successful implementing knowledge management (Ghorbanizadeh, Nourbakhsh, \& Mansourian, 2009). Iranian society has to consider meritocracy in its bureaucracy system and this is reflected in the context of general policies of bureaucracy system. As policies emphasize the importance of meritocracy in organizations, if it is done properly, it will make constitutive effects on Iranian society.

\section{Human Role in Knowledge-based Organization}

Another argumentative fact about knowledge-based organization is the human and behavior roles in knowledge making. Despite immediate evolutions and developments in communication and information technologies, human role is issued as the most principle factor in discovering knowledge. Interestingly, it is made in human minds, but no one knows how this happens. Knowledge is obtained, transmitted and distributed by human minds, and finally it is utilized by the people who embraced it. If we recognize recording, receiving and applying knowledge as a hard function in knowledge-based organizations, creating and transmitting knowledge is considered soft functions. The hard function implicates aiding roles of machine and hardware and soft function shows that human and his/her mind is active and influencing. If knowledge is not distributed and utilized, it will not be influencing. Hence, knowledge is formed, developed and utilized through human. The organizational knowledge is formed through interacting among humans by technologies. In other words, creating knowledge is the superior ability of human and his predominance reason against other animals and intelligent artificial technologies. This is just human beings who possess the ability and potential of knowledge building (Alvani, 2016).

To encounter with either varying environment or rapid increasing of technology, skills and knowledge, an organization needs learning for synchronizing with these changes. Thus, it is 
obvious that a knowledge-based organization should be a learning organization, too (Hassani, 2014).

Peter (1990) defines learning organization whose members are always developing potentials in order to make the expected results, where modern and extended thinking models are fostered, group thought are freely promoted and individuals are continuously learnt how to learn. Gravin (1993) defines learning organization as an organization with five major processes:

\section{Issues and Problems Solving in a Systemic Way}

Organization must recognize its problems and issues and achieve to their solution by providing assumptions and examining them. Learning organization neither disappoint by problems and issues nor escape from them rather it accepts them conveniently and this is the starting point of improvement and reformation (Alvani, 2008).

\section{Test and Experience}

This is the second action by learning organization, which contributes with searching and examining new knowledge. Organization purpose is not eliminating current problem in this function; but it speculates the future and response to the expecting problems by obtaining new knowledge and adjusting it with environment. Test and experience lead knowledge and since all employees and members of the organization are engaged in this process, we have a kind of cumulative knowledge which is compatible with the environment and the atmosphere of organization. (Hassani, 2014)

\section{Learning from Past}

Learning organization learns from its past experiences and keeps them in its memory. Reviewing fails and successes and finding their reason is very instructive. Learning organization must make the gained knowledge resolvable and accessible in any way; as all members and units could exploit the cumulative and collected knowledge, if required (Alvani, 2008).

\section{Learning from the Others through Imitating the Best}

Learning organization not only makes knowledge depending on its experiences, but also provides it by learning from the others. Imitating is based on explicit knowledge; while benchmarking considers tacit knowledge. This means, we find the logic of standards in benchmarking, rather than regarding their shape and appearance; and get through them and understand them deeply. Humans must comprehend scientific modesty and humility and consider his needs and deficiencies in a field. There is no opportunity for improvement regarding the people who are engaged in vanity. (Hassani, 2014)

\section{Transmitting and Distributing Knowledge}

Learning organization must be able to obtain, attract and create knowledge, record it and distribute it in an appropriate way. Knowledge should not be confined in a specific group minds, it must be distributed in the whole organization and among all members. Thoughts and ideas are mostly efficient when they are distributed among all people. Therefore, we should struggle to distribute knowledge through verbal, oral and written instruments, and different didactic methods. Through proficiency in these all five functions, an organization becomes learner, producer and distribute of knowledge in a substantial way. Therefore, knowledge-based organization must be able to learn, gain and record the obtained knowledge through learning, until it could work as an experienced organization (Alvani, 2008). 


\section{Research Background}

Dimovski and Penge (2004) have provided indictors of knowledge-based organizations and developing learning organization through learning framework in knowledge-based economy of Slovenia. They created the Knowledge Based Organization through Learning Implementation Framework, i.e. Conceptual Model of Slovenia Enterprises. By studying literature related to learning organization and knowledge management and utilizing the obtained framework though theoretical and practical methods among Slovenian enterprises, they presented a conceptual framework which shows the approaching way to knowledge-based organization paradigm in knowledge-based economy.

Neagu (2008) has prepared a model for identifying knowledge-based organizations according to six aspects including knowledge employee, organizational structure, organizational culture, knowledge building, management, and ICT technology. Determining parameters of each criterion was according to literature reviews. Then, he analyzed the knowledge dependency of a water supply organization in Romania.

Huang and Lai (2012) showed the Critical Successful Factors (CSFs) of knowledge management using structure equation modeling. They categorized these CSFs into environments, individual characteristics, knowledge management characteristics, organizational characteristics, IT infrastructure, culture factors, and knowledge management implementation. They concluded that environments had a significant effect on organizational characteristics. Moreover, environments and IT infrastructure affected knowledge management characteristics, and both knowledge management characteristics and organizational characteristics influenced knowledge management implementation.

Abbas, Rasheed, Habiba, and Shahzad (2013) studied the factors promoting knowledge sharing and knowledge creation in banking sector of Pakistan. They reported that the knowledge sharing and knowledge creation were the keys for the success of an organization. They also reported that a firm or an organization could sustain its competitive edge in market with the help of Knowledge sharing and knowledge creation.

Hellebrandt, Heine, and Schmitt (2018) present a methodological framework based on the analytical network process (ANP) approach for selecting knowledge management solutions for transferring complaint knowledge to new product developments. Based on an extensive literature review and prior research projects, competing objectives, diverse criteria as well as various organization-specific factors have been identified and integrated into the framework. A study amongst 15 knowledge management experts was conducted to evaluate knowledge management solutions with respect to the identified objectives and selection criteria. Additionally, the practical applicability was tested in a case study in the German machinery and equipment industry. The framework exceeds existing approaches to technical complaint management (TCM) in enabling a more elaborated design of the long-term knowledge transfer phase within the TCM process. In this regard, the framework provides a systematic approach to assist practitioners in selecting knowledge management solutions for a specific organizational setting. Several universal implications for selecting knowledge management solutions in the context of TCM were derived from the results of the expert study and the case study (e.g., most favorable KM solutions for single criteria). These findings enable an effective and efficient transfer of complaint knowledge to future product developments, and thus facilitate the design of a more sustainable and improved TCM process. 
Zakaria and Sulaiman (2018) believe that social network such as Facebook is an innovative knowledge sharing technology. The increasing use of social network each year has shown that these effective medium can be extended beyond simple communication within a community.

Yazdi and Haddadi (2018) attempted to investigate the road map of critical successful factors (CSFs) of knowledge management in Iranian insurance companies. In this study, the Rembrandt method, being the optimized form of the analytical hierarchy process (AHP), was used to determine which critical successful factors were suitable for the implementation of knowledge management in organizations. In each organization, there are many vital issues-some more important than others-that must be considered. No organization can implement knowledge management improvement programs (KMIPs). The road map provided in this article will help Iranian insurance managers better prioritize and allocate their limited resources to CSFs.

Aramoon and Aramoon (2019) performed identifying and prioritizing the cultural factors effective on the successful implementation of knowledge management in the industry of electronic insurance services. The study statistical population included 30 managers of companies active in the insurance industry in Iran. Followed by collecting the research data through a questionnaire distributed among the members of the statistical population, first prioritized the six main factors based on the impact level using the fuzzy network analysis technique. The results revealed that the knowledge creation culture factor is ranked first. In the end, the components of each of the cultural factors affecting the implementation of knowledge management were ranked using the fuzzy TOPSIS technique. Accordingly, one can acknowledge that the cultural factors play a crucial role in determining the results of knowledge management efforts. For this reason, the organizations intending to implement knowledge management need to evaluate the cultural factors affecting the successful implementation of knowledge management.

In summary, the studies mentioned above have looked at knowledge management and its accomplishment necessities with different approaches. Some of them have emphasized on key factors including formality, centralization, leaning culture and ... directly, and some others supported the substantial criteria or a specific standard such as culture or structure in higher level. According to the mentioned facts, there are three principles which are supported by the most researchers including structure, culture and behavior (human source), which constitute major part of an organization. Therefore, we have searched for major parameters and subsets by studying articles, books and research background, and provided some specific components through examining and evaluating concepts and comparisons and their combination.

\section{Research Methodology}

In this research, a research-made questionnaire was used to collect the data. The content validity and reliability of the questionnaire were reported. The content validity is a kind of validity which is usually applied to study the components of a measuring tool. In fact, this kind of validity is a process to determine indicators of questions regarding characteristics, skills, knowledge and what is measured. For determining reliability of the questionnaire, Cronbach's Alpha method was used. This method is applied to calculate internal adjustment of measuring tool which measures different characteristics. Using the re-test technique, the questionnaire was twice distributed among a number of 30 experts and then collected. The results showed that the value of Cronbach's Alpha coefficient has been higher than $90 \%$ and this number represents the existence of an acceptable reliability for the used tool. 
AHP has become one of the most popular decision-making methods due to the use of pairwise comparisons to input qualitative information (Zakaria \& Sulaiman 2018). There are numerous types of previous studies regarding AHP which enables people to make decisions including applications in knowledge management system (Greco, Cricelli, \& Grimaldi, 2013), and Online Business Network (Zakaria \& Sulaiman 2018). Hence, AHP helps decision makers in comparing the relative importance of the factors or criteria in a systematic and quantitative manner. Therefore, the application of AHP in this study is robust and does not constitute any biased results as the judgment on the weights depends on the respondents' decision.

The present study followed stages of identifying accomplishment criteria for knowledge-based organization, preparing first stage questionnaire and distributing among experts and analyzing it, building sequential structure, preparing second stage questionnaire and distributing among experts, determining double matrixes of major criteria and substandard relating to each major criterion, computing weight significance of criteria and substandard, and finally analyzing them.

\section{Results}

The first stage of identifying accomplishment criteria for knowledge-based organization includes: literature reviewing about knowledge-based organization, major criteria and substandard collection were identified as the accomplishment criteria in knowledge-based organization, which were divided into 3 major criteria and 18 substandard. Second stage includes preparing questionnaire and distributing among experts and analyzing it. These experts were 30 instructors in governmental management of national and Azad universities.

After extracting accomplishment criteria of knowledge-based organization, in order to determine whether it is necessary or not, these criteria were characterized according to the experts' opinion about each parameter in knowledge-based organization. Finally, as it is shown in Table 1, key factors for accomplishing knowledge-based organization were identified.

Table 1

Key Factors for Accomplishing Knowledge-Based Organization

\begin{tabular}{ll}
\hline Substandard & Major criteria \\
\hline 2) eliminate of boundary & Structural \\
3) flexibility & \\
4) information technology & \\
5) applying teams and awarding them & \\
6) formality & \\
7) centralization & Behavioral \\
8) complexity & \\
1) issues and problem solving in a systemic way & \\
2) test and experience & \\
3) learning from past & \\
4) imitating the best & \\
5) transmitting and distributing knowledge & \\
1) Islamic and religious values & \\
2) participation & \\
3) trust & \\
4) knowledge fostering leading & \\
5) meritocracy & \\
\hline
\end{tabular}


In the third stage of building sequential structure, different levels of decision making and their constituents were determined in a sequential way. The first level includes rating accomplishment criteria for knowledge-based organization. In the second level, 3 major criteria for accomplishing knowledge-based organization were introduced and finally in the third level there were substandard related to each major criterion (Figure 1).

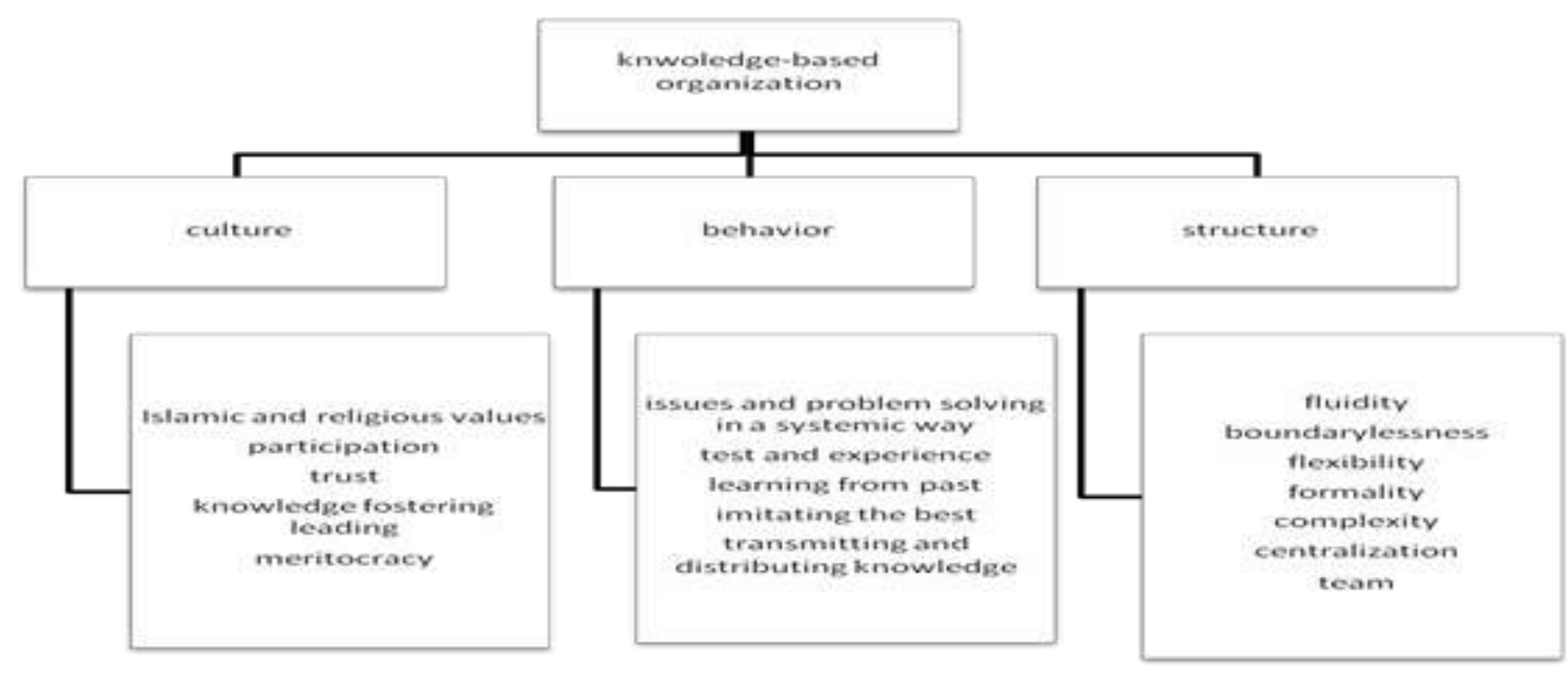

Figure 1. Sequential Structure

The fourth part includes preparing second stage questionnaire and distributing it among experts. Following above-mentioned stages, a standard questionnaire was designed depending on sequential analysis and then it was distributed among experts.

In the fifth part of determining double matrixes of major criteria and substandard relating to each major criterion, the ideas of experts were integrated using geometrical average. Integrated double matrixes are presented in Table 2, 3, 4 and 5.

Table 2

Double Matrixes of Comparing Major Criteria

\begin{tabular}{lccc}
\hline & Structural criteria & Behavioral criteria & Cultural criteria \\
\hline Structural criteria (S) & 1 & 3.12 & 1.29 \\
Behavioral criteria (B) & & 1 & 2.071 \\
Cultural criteria (C) & & & 1 \\
\hline
\end{tabular}

Table 3

Double Comparing Matrix of Structural Criteria

\begin{tabular}{|c|c|c|c|c|c|c|c|c|}
\hline & $\begin{array}{l}\text { Fluidity } \\
\text { (S1) }\end{array}$ & $\begin{array}{c}\text { Boundary } \\
\text { lessness (S2) }\end{array}$ & $\begin{array}{l}\text { Flexibility } \\
\text { (S3) }\end{array}$ & $\begin{array}{c}\text { Technology } \\
\text { (S4) }\end{array}$ & $\begin{array}{l}\text { Formality } \\
\text { (S5) }\end{array}$ & $\begin{array}{c}\text { Centralization } \\
\text { (S6) }\end{array}$ & $\begin{array}{l}\text { Complexity } \\
\text { (S7) }\end{array}$ & $\begin{array}{l}\text { Team } \\
\text { (S8) }\end{array}$ \\
\hline Fluidity (S1) & 1 & 1.09 & 1.28 & 1.17 & 1.87 & 1.91 & 2.16 & 1.18 \\
\hline $\begin{array}{l}\text { Boundary } \\
\text { lessness (S2) }\end{array}$ & & 1 & 1.25 & 2.66 & 1.83 & 2.25 & 2.32 & 1.31 \\
\hline Flexibility (S3) & & & 1 & 1.42 & 3.27 & 3.44 & 3.37 & 1.11 \\
\hline Technology (S4) & & & & 1 & 2.17 & 2.46 & 2.44 & 1.42 \\
\hline Formality (S5) & & & & & 1 & 2.14 & 1.76 & 1.41 \\
\hline $\begin{array}{l}\text { Centralization } \\
\text { (S6) }\end{array}$ & & & & & & 1 & 1.44 & 1.29 \\
\hline Complexity (S7) & & & & & & & 1 & 1.26 \\
\hline Team (S8) & & & & & & & & 1 \\
\hline
\end{tabular}


Table 4

Double Comparing Matrix of Behavioral Criteria

\begin{tabular}{lccccc}
\hline & $\begin{array}{c}\text { issues and } \\
\text { problem solving } \\
\text { in a systemic } \\
\text { way } \\
\text { (B1) }\end{array}$ & $\begin{array}{c}\text { test and } \\
\text { experience } \\
\text { (B2) }\end{array}$ & $\begin{array}{c}\text { learning from } \\
\text { past (B3) }\end{array}$ & $\begin{array}{c}\text { imitating the } \\
\text { best (B4) }\end{array}$ & $\begin{array}{c}\text { transmitting and } \\
\text { distributing } \\
\text { knowledge (B5) }\end{array}$ \\
\hline $\begin{array}{l}\text { Issues and problem Solving in a } \\
\text { systemic way }\end{array}$ & 1 & 5.47 & 3.43 & 2.05 & 2.24 \\
$\begin{array}{l}\text { Test and experience (B2) } \\
\text { Learning from past (B3) }\end{array}$ & 1 & 1.07 & 1.09 & 1.02 \\
$\begin{array}{l}\text { Imitating the best (B4) } \\
\text { Transmitting and Distributing } \\
\text { knowledge (B5) }\end{array}$ & & & 1 & 1.38 & 1.09 \\
\hline
\end{tabular}

Table 5

Double Comparing Matrix of Cultural Criteria

\begin{tabular}{lccccc}
\hline & $\begin{array}{c}\text { Islamic and } \\
\text { religious } \\
\text { values (C1) }\end{array}$ & $\begin{array}{c}\text { Participation } \\
(\mathrm{C} 2)\end{array}$ & Trust (C3) & $\begin{array}{c}\text { knowledge } \\
\text { fostering } \\
\text { leading (C4) }\end{array}$ & $\begin{array}{c}\text { Meritocracy } \\
\text { (C5) }\end{array}$ \\
\hline Islamic and religious values (C1) & 1 & 1.19 & 1.24 & 1.08 & 1.06 \\
Participation (C2) & & 1 & 1.47 & 2.88 & 1.38 \\
Trust (C3) & & & 1 & 3.61 & 1.10 \\
knowledge fostering leading (C4) & & & & 1 & 1.32 \\
Meritocracy (C5) & & & & 1 \\
\hline
\end{tabular}

\section{Transformational Leadership and Service Quality}

The Fifth stage is related to the computing weight significance of criteria and substandard. Expert Choice software was used for analyzing data in this research. To do this, all research parameters were imported to the software according to the sequential structure of research. Then integrating matrixes, obtained in the last stage, were imported to the software in order to determine the weight of each one. Finally, relative weight of all criteria were presented in Table 6 :

Table 6

Weight Significance of 18 Criteria

\begin{tabular}{|c|c|c|}
\hline Relative weight & Criteria & number \\
\hline 0.068 & S1 - fluidity & 1 \\
\hline 0.0 .62 & $\mathrm{~S} 2$ - eliminate boundary & 2 \\
\hline 0.090 & S3 - flexibility & 3 \\
\hline 0.098 & $\mathrm{~S} 4$ - information technology & 4 \\
\hline 0.042 & S5 - formality & 5 \\
\hline 0.030 & S6 - centralization & 6 \\
\hline 0.033 & S7 - complexity & 7 \\
\hline 0.059 & S8 - team & 8 \\
\hline 0.039 & B1 - issues and problem solving in a systemic way & 9 \\
\hline 0.011 & $\mathrm{~B} 2$ - test and experience & 10 \\
\hline 0.011 & B3 - learning from past & 11 \\
\hline 0.017 & B4 - imitating the best & 12 \\
\hline 0.012 & B5 - transmitting and distributing knowledge & 13 \\
\hline 0.079 & $\mathrm{C} 1$ - Islamic and religious values & 14 \\
\hline 0.101 & $\mathrm{C} 2$ - participation & 15 \\
\hline 0.102 & $\mathrm{C} 3$ - trust & 16 \\
\hline 0.051 & $\mathrm{C} 4$ - knowledge fostering leading & 17 \\
\hline 0.094 & C5 - meritocracy & 18 \\
\hline
\end{tabular}




\section{Discussion and Sensitive Analysis}

Applying inappropriate criteria in order to succeed in knowledge-based organization makes organizations fail. According to the importance of identifying accomplishment criteria for knowledge-based organizations and also depending on different influencing rate of each criterion, standards of accomplishments for knowledge-based organizations were prioritized considering ideas of experts (Table 7).

Table 7

Rating 3 Major Criteria

\begin{tabular}{ccc}
\hline Weight value & Criteria & rank \\
\hline .42 & Cultural & 1 \\
.41 & Structural & 1 \\
.16 & Behavioral & 1 \\
\hline
\end{tabular}

By collecting the questionnaires of first and second stage, and analyzing second questionnaire using the software, according to findings presented in Table 7, cultural criteria is the most important criteria which is applied in the accomplishing knowledge-based organization. The sensitivity of this criteria against current condition is 48 percent and the sensitivity of structural criteria place in the next priorities is 29 percent. According to the results, general rating of all substandard is illustrated in Table 8 and Figure 2.

Table 8

Final Prioritizing of Substandard for Knowledge-based Organization

\begin{tabular}{ccc}
\hline Weight value & Substandard & rank \\
\hline 0.102 & C3 - trust & 1 \\
0.101 & C2 - participation & 3 \\
0.098 & S4 - information technology & 4 \\
0.094 & C5 - meritocracy & 5 \\
0.090 & S3 - flexibility & 6 \\
0.079 & C1 - Islamic and religious values & 7 \\
0.068 & S1 - fluidity & 8 \\
0.062 & S2 - boundary eliminate of & 9 \\
0.059 & S8 - team depending and awarding them & 10 \\
0.051 & C4 - knowledge fostering leading & 11 \\
0.042 & S5 - formality & 12 \\
0.039 & B1 - issues and problem solving in a systemic way & 13 \\
0.033 & S7 - complexity & 14 \\
0.017 & S6 - centralization & 15 \\
0.012 & B4 - imitating the best & 16 \\
0.011 & B5 - transmitting and distributing knowledge & 17
\end{tabular}


Trust

association

Information technology

Meritocracy

Flexibility

Refigious values

Fluidity

Boundary-less ness

Team

Learning

formalization

Solving systematic peoblems

complexity

Centralization

Benchmarking

Knowledge transfer and dissemination

Exreriment and experience

Learning from the past

\section{Overall Inconsistency $=.04$}

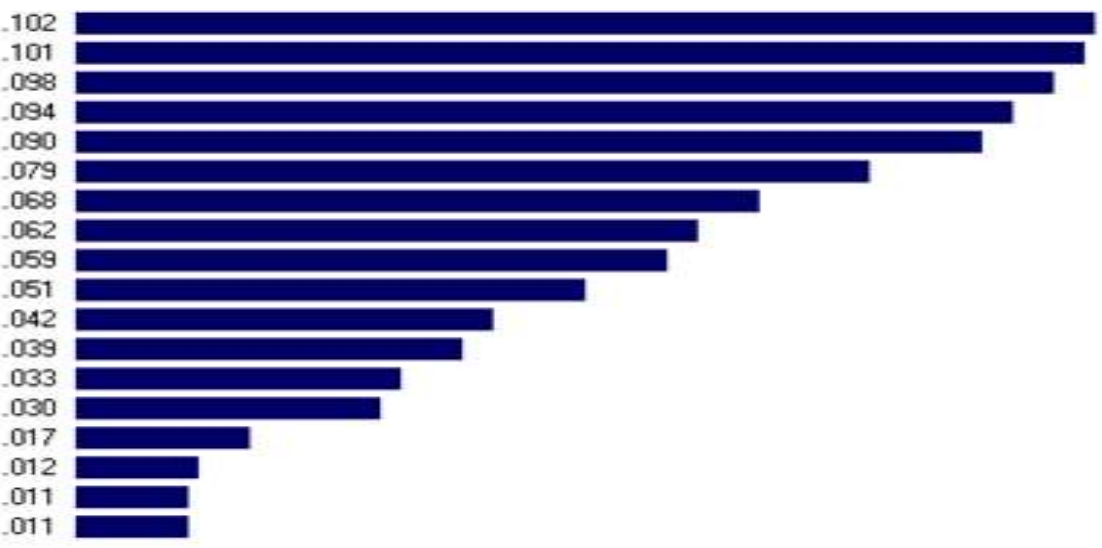

Figure 2. Final prioritizing of substandard for knowledge-based organization

Prioritizing and sensitive analysis is an important task. Sensitive analysis analyzes results against values of prioritizing criteria. The results related to dynamic sensitivity are presented in Figure 3. This analysis shows the importance of major criteria and influencing determination of these variations on total prioritizing substandard for dynamic change. The results are presented by two dynamic sensitivity analysis of Figure 3 and performance sensitivity analysis of Figure 4.

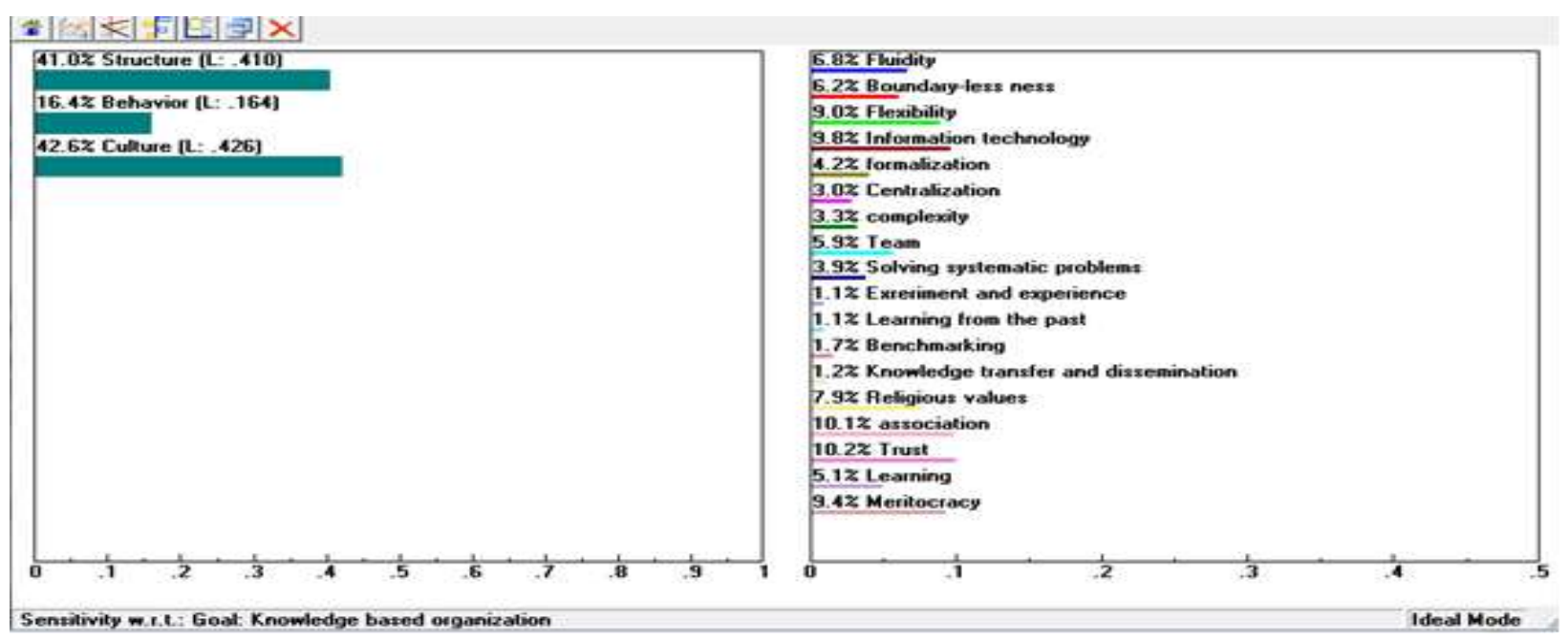

Figure 3. Dynamic graph of sensitivity analysis

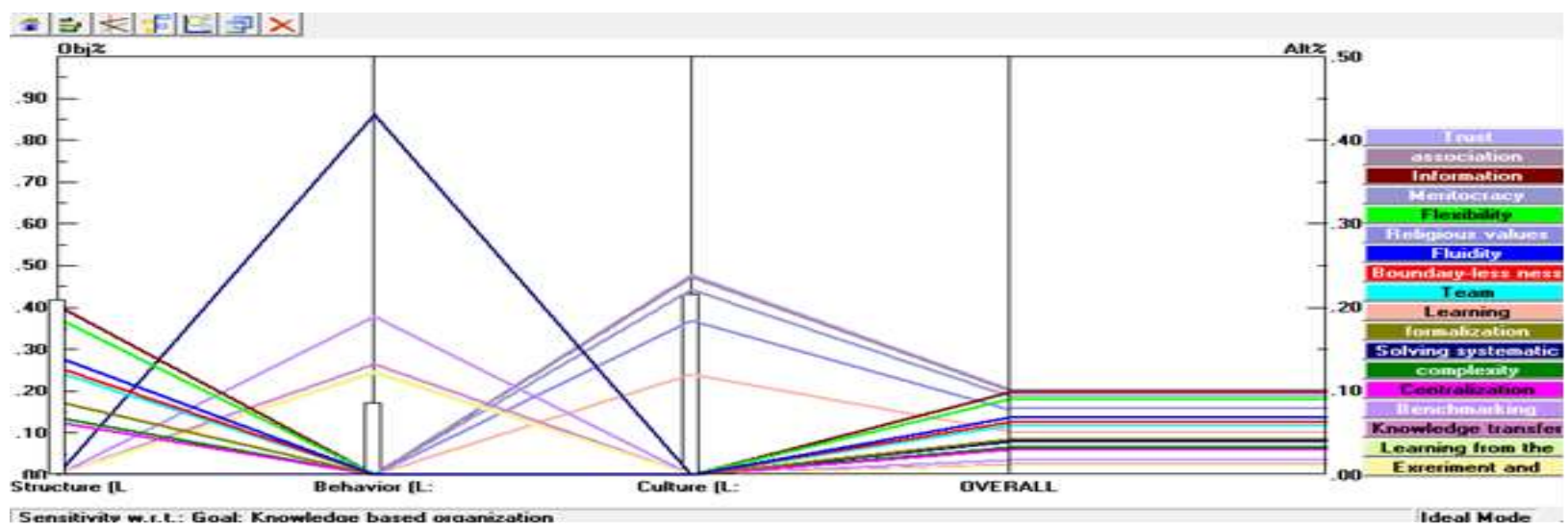

Figure 4. Performance sensitivity analysis graph 
As shown in Figure 3 and examining major criteria sensitivity in the software, it is concluded that whenever relative weight of behavior (behavioral criteria) changes more than 97 percent, "issues and problem solving in a systemic way" substandard is the most criteria among all criteria; in other words, it is not sensitive about 97 percent. If relative weight of major criteria of culture (cultural criteria) changes about 48 percent, "information technology" will be the most significant criteria; in other words, it is not sensitive about 48 percent. If relative weight of major criteria of structure (structural criteria) changes 29 percent, "trust" criteria will be the most important criteria; in other words, it is not sensitive about 29 percent.

\section{Conclusion}

This study aimed to identify and prioritize key factors of accomplishing knowledge-based organization. The results show that the key factors of accomplishing knowledge-based organization are importantly cultural, structural and behavioral criteria, respectively. According to the results, cultural criteria is divided into five substandard (trust depending culture, participation culture, meritocracy culture, Islamic and religious values and knowledge fostering leading) and eight substandard of structural criteria (information technology, flexibility, fluidity, boundarylessness, team dependency and awarding them, formality, complexity and centralization) and behavioral criteria (issues and problem solving in a systemic way, learning from others, transmitting and distributing knowledge, test and experience and learning from past), which is necessary for managers to consider them in a special manner when providing a knowledge-based organization. In general, according to the results, one can admit that the cultural, structural and behavioral factors play a crucial role in determining the results of knowledge management efforts. For this reason, the organizations intending to implement knowledge management need to evaluate the cultural, structural and behavioral factors affecting the successful implementation of knowledge management. The important implication of this study is that the key factors of accomplishment for knowledge-based organization identified in this study can aid managers in establishing knowledgebased organization.

\section{References}

Abbas, F., Rasheed, A., Habiba, U., \& Shahzad, I. (2013). Factors promoting knowledge sharing and knowledge creation in banking sector of Pakistan. Management Science Letters, 3(2), 405-414.

Ajmal, M. A., Petri, H. (2010). Organizational culture and knowledge management: An empirical study in Finnish project-based companies. Innovation and Learning, 7(3), 333-344.

Alvani, S. M. (2008), knowledge building approaches, and their survival necessity in modern organizations [In Persian]. Parliament and Research Magazine, Tenth Year, 41, 15-39.

Alvani, S. M. (2014). Public issues management [In Persian] Tehran: Programming and Management Educating and Research Institute.

Alvani, S. M. (2016). Public management [In Persian]. Tehran: Ney Publication.

Aramoon, E., \& Aramoon, V. (2019). Identifying and prioritizing the cultural factors effective on the successful implementation of knowledge management in the industry of electronic insurance services. Romanian Journal of Information Technology and Automatic Control, 29(2), 69-84.

Cavaleri, S. A. (2004) Leveraging organizational learning for knowledge and performance. The Learning Organization, 11(2), 159-176.

Cazier, J. A, Shao, B. M., \& Louis., R. D. S. (2007). Sharing information and building trust through value congruence. Published online: Springer Science, BusinessMedia, and LLC.

Chang, M. Y., Hung, Y. C., Yen, D. C., \& Tseng, P. T. (2009). The research on the critical success factors of knowledge management and classification framework project in the Executive Yuan of Taiwan Government. Expert Systems with Applications, 36(3), 5376-5386. 
de Barros Jerônimo, T., de Melo, F. J. C., de Aquino, J. T., de Albuquerque, A. P. G., \& de Medeiros, D. D. (2018). Knowledge management alignment to the community of practice in a company of cutting and bending steel. Brazilian Journal of Operations and Production Management, 15(1), 1-11.

Dimovski, V., \& Penge, S. (2004). Creating the knowledge based organization through learning implementation framework: conceptual model of Slovenia enterprises. International Journal of Business and Economics, 3, $73-88$.

Goh, S. C. (2002). Managing effective knowledge transfer: An integrative framework and some practice implication. Journal of Knowledge Management, 6(1), 23-30.

Ghorbanizadeh, V., Nourbakhsh, M., \& Mansourian, E. (2009). Critical factors of knowledge management success in public organizations [In Persian]. Police Investigations Magazine, 6(3), 470-486.

Graham, A. B., \& Pizzo, V. G. (1996). A question of balance: Case studies in strategic knowledge management. European Management Journal, 14(4), 338-346.

Garvin, D. A. (1993). Building a learning organization. Harvard Business Review, 71(4), 78-91.

Greco, M., Cricelli, L., \& Grimaldi, M. (2013). A strategic management framework of tangible and intangible assets. European Management Journal, 31(1), 55-66.

Hassani, S. (2014). Providing a model for measuring knowledge level in organizations (Unpublished master's thesis) [In Persian]. Tarbiat Modarres University, Tehran.

Hellebrandt, T., Heine, I., \& Schmitt, R. H. (2018). ANP-based knowledge management solutions framework for the long-term complaint knowledge transfer. Total Quality Management and Business Excellence, 29(9-10), 1074-1088.

Hsu, M. H., Ju, T. L., Yen, C. H., \& Chang, C. M. (2007). Knowledge sharing behavior in virtual communities: The relationship between trust, self-efficacy, and outcome expectations. International Journal of Human-Computer Studies, 65(2), 153-169.

Huang, L. S., \& Lai, C. P. (2012). An investigation on critical success factors for knowledge management using structural equation modeling. Procedia-Social and Behavioral Sciences, 40, 24-30.

Liao, S. H., Chang, W. J., \& Wu, C. C. (2010). An integrated model for learning organization with strategic view: Benchmarking in the knowledge-intensive industry. Expert Systems with Applications, 37(5), 3792-3798.

Liu, Y. C. (2011). Applying social capital and SECI model to explore gender differences in knowledge sharing behaviors. International Journal of Digital Society, 2(3), 512-519.

Martina, K., Hana, U., Jiř́, F., Iveta, ̌̌., Abraham, A., Jebapriya, S., \& de Matos, A. C. (2012). Identification of managerial competencies in knowledge-based organizations. Journal of Competitiveness, 4(1), 129-142.

Miller, D., \& Droge, C. (1986). Psychological and traditional determinants of structure. Administrative Science Quarterly, 31, 539-560.

Monavvarian, A, Kheir Andish, M., \& Asgari, N. (2013), developing structural criteria of organization, appropriating with knowledge management approach [In Persian]. Information Technology, 7, 133-150.

Nasr Esfahani, M., \& Nasr Esfahani, A. (2009). Qualification of society management emphasizing to political thoughts of Imam Ali [In Persian]. Political Cognition Magazine, 2, 141-160.

Neagu, C. D. (2008). Knowledge based organization. In IFIP International Summer School on the Future of Identity in the Information Society. Boston, MA: Springer.

Peter, S. E. N. G. E. (1990). The leader's new work: Building learning organizations. Sloan Management Review, 32(1), 7-23.

Starbuck, W. (1992). Learning by knowledge intensive firms. Journal of management studies, 9(6), 713-740.

Stock, G. N., McFadden, K. L., \& Gowen, III, C. R. (2007). Organizational culture, critical success factors, and the reduction of hospital errors. International Journal of Production Economics, 106(2), 368-392.

Tocan, M. C. (2012). Knowledge based strategies for knowledge based organizations. Journal of Knowledge Management, Economics and Information Technology, 2(6), 167-177.

Wang, C. L., \& Ahmed, P. K. (2003). Structure and structural dimensions for knowledge-based organizations. Measuring Business Excellence, 7(1), 51-62.

Wasko, M. M., \& Faraj, S. (2005). Why should I share? Examining social and knowledge capital contribution in electronic of networks of practice. MIS Quarterly, 29(1), 35-57.

Yazdi, A. K., \& Haddadi, M. (2018). Prioritizing critical successful factors of knowledge management in insurance companies. International Journal of Operational Research, 31(3), 281-299.

Zack, M. H. (2003). Knowledge based strategies for knowledge based organizations. Paper presented at the Fifth Conference on Organizational Learning and Knowledge, England.

Zahedi, S., \& Kheir Andish, M, (2008). Explaining structural factors in knowledge-based economy [In Persian]. Journal of Iran Management Science, 6, 49-68. 
Zakaria, R., \& Sulaiman, N. S. (2018). Measuring important success factors in knowledge sharing behavior among online business network users using analytical hierarchy process. International Journal of Accounting, Finance and Business, 3(12), 91-100. 